\title{
Development and use of behavior and social interaction software installed on Palm handheld for observation of a child's social interactions with the environment
}

\author{
ARCHANA SARKAR \\ Annamalai University, New Delhi, India \\ ARUP DUTTA and USHA DHINGRA \\ Johns Hopkins Bloomberg School of Public Health, Baltimore, Maryland \\ PRATIBHA DHINGRA, PRITI VERMA, and RAKESH JUYAL \\ Annamalai University, New Delhi, India \\ ROBERT E. BLACK \\ Johns Hopkins Bloomberg School of Public Health, Baltimore, Maryland \\ VENUGOPAL P. MENON and JITENDRA KUMAR \\ Annamalai University, New Delhi, India \\ and \\ SUNIL SAZAWAL \\ Annamalai University, New Delhi, India \\ and Johns Hopkins Bloomberg School of Public Health, Baltimore, Maryland
}

\begin{abstract}
In settings in developing countries, children often socialize with multiple socializing agents (peers, siblings, neighbors) apart from their parents, and thus, a measurement of a child's social interactions should be expanded beyond parental interactions. Since the environment plays a role in shaping a child's development, the measurement of child-socializing agents' interactions is important. We developed and used a computerized observational software Behavior and Social Interaction Software (BASIS) with a preloaded coding scheme installed on a handheld Palm device to record complex observations of interactions between children and socializing agents. Using BASIS, social interaction assessments were conducted on 573 preschool children for $1 \mathrm{~h}$ in their natural settings. Multiple screens with a set of choices in each screen were designed that included the child's location, broad activity, state, and interactions with child-socializing agents. Data were downloaded onto a computer and systematically analyzed. BASIS, installed on Palm OS (M-125), enabled the recording of the complex interactions of child-socializing agents that could not be recorded with manual forms. Thus, this tool provides an innovative and relatively accurate method for the systematic recording of social interactions in an unrestricted environment.
\end{abstract}

The overall development of a child has multiple determinants, and the interaction between them contributes significantly to the developmental process (Clark, Paulson, \& Conlin, 1993; Humber \& Moss, 2005). The quality of a child's interaction with the social environment is one of the important determinants of his or her development

This research was supported by New Zealand Milk Limited, Private Bag 12032, Auckland, New Zealand. We thank the parents of the participating children for their time and cooperation. Correspondence concerning this article should be addressed to S. Sazawal, W5517, Department of International Health, Johns Hopkins Bloomberg School of Public Health, 615 North Wolfe Street, Baltimore, MD 21205 (e-mail: ssazawal@jhsph.edu).
(Bronfenbrenner, 1986; Hoff, 2003; Horodynski \& Gibbons, 2004; Vygotsky, 1979). Traditionally, the parentchild interaction has been considered to be the only critical component of the social environment; but in a setting in a developing country, children interact with various other socializing agents, such as siblings, peers, neighbors, and relatives, many times more than they interact with parents. A structured assessment measuring a child's interactions with other socializing agents, along with parents, in a natural setting is thus important and potentially will influence evaluations of the effect of the environment on the child's development and behavior.

Studies of child interactions have focused mainly on measuring the quality of mother-child interactions in a 
structured clinical or playroom setting (Barnard, 1979; Caldwell \& Bradeley, 1978; Cardone \& Gilkerson, 1990; Clark, Musick, Stott, Klehr, \& Cohler, 1984; Farran, Clark, \& Ray, 1990; Greenspan \& Leiberman, 1980). A few studies have evaluated peer play and social behavior among preschool children (Coplan \& Parke, 1999). But there is no study available that has assessed the interactions of the child with multiple socializing agents at a given time in the natural environment of the child. Most of the studies in which the social interaction of a mother and a child have been assessed have used the manual recording method of direct observation, which is cumbersome and prone to observation errors and has resulted in inconsistencies in data recording and analysis (Bakeman \& Gottman, 1986; Berdondini et al., 1999; Martin \& Bateson, 1986). Recently, a Palm handheld device using customized software has gained popularity and has been found to be a versatile and economical alternative for recording observational and clinical data in field settings (Koop \& Mösges, 2001; Plant, Hammond, \& Turner, 2004; Selanikio, Kemmer, Bovill, \& Geisler, 2002).

Therefore, to study children's interactions with the environment, as a determinant in a clinical trial that was evaluating the effect of nutrition intervention on cognitive development, we developed an observational software with a comprehensive coding scheme that could provide a flexible, computer-based coding system for observing, recording, and storing complex and rapidly exhibited behavioral data. The present article describes the background and development of the BASIS software, coding schemes, and field implementation. A descriptive account is presented because there is no other gold standard tool available for comparative evaluation. Information on the collection and analysis of a sample is provided so that the reader will be able to understand the use of the method.

\section{Methodology}

Conceptual background. The constructs developed in this study for assessing the interaction between a child and socializing agents were based on the conceptual background provided by studies of mother-child interactions and the social behavior of children. Studies on mother-child interactions have focused mainly on assessing acceptance/rejection behavior toward the child by the mother (Rohner, 1999) and the intensity of the child's behavior toward the mother or any other socializing agents (Pollitt, Saco-Pollitt, Jahari, Husaini, \& Huang, 2000). Acceptance has been considered as a positive behavioral display, such as affection, nurturance, positive response, gesture, or playfulness, and rejection as a negative behavioral display, such as aggression, neglect, or indifference toward the child by the mother (Ainsworth, Blehar, Waters, \& Wall, 1978; Clark, 1985; Demos, 1982; Emde, 1980).

Development of observation software in Palm. On the basis of the literature, we identified and suitably modified 12 behavioral categories, each of which further contained a set of behavioral codes (in the form of choices) for recording these categories. These were designed in such a way as to comprehensively record a child's interaction with his/her socializing agents, as well as the interaction of the socializing agents with the child, in a natural setting. We also defined the setting, situation, and state of the child in the software used for recording the child's broad behavior during an observation session. Setting consisted of the location of the child (inside the home/outside the home); situation was a broad activity in which the child was engaged for more than a minute; and state recorded the general behavioral state of the child during the observation session. Agents were the specific socializing agents with whom the child interacted, such as the mother, father, neighbor, siblings, peer, or any object with which the child played, such as a toy. The details of the categories and behavioral codes for a child's setting, situation, state, and interactions with child-socializing agents are presented in the Appendix. The behavioral categories and codes that we included in this study were discussed with experts and were pretested on 20 children in a field setting in order to check their appropriateness and suitability for recording observations of the social interactions of children with their socializing agents.

BASIS was designed using Visual Basic 6.0 software integrated with AppForge Crossfire. A Palm database was used to record the data at backend. The software was compiled to a Palm-based executable file and uploaded to the Palm OS (M-125 series) handheld device with support files necessary to run the application. This configuration ensured that the coding scheme could be preloaded for independent variables, setting, situation, state, and interactions of childsocializing agents, so that input could be recognized during observations. Independent variables were defined as a child's identification number, age, and gender.

BASIS operates in an interactive fashion with multiple screens representing a set of choices for a particular behavioral category, enabling the examiner to select one with the help of a stylus, which gets recorded by time with other parameters, such as setting, situation, state, and agents. All the codes and categories in the screens are displayed in short sentences, and no abbreviations are used.

The initial screen had five option buttons, of which three buttons were used to record the codes for setting, situation, and state during the observation period. Whenever there was a change in any one of the three codes for more than $1 \mathrm{~min}$, it was recorded, and software automatically kept track of the duration by recording the starting and end times of the changes. The other two option buttons were for recording the child-socializing agents' interactions: one for selecting child-initiated interactions and the other for socializing-agent-initiated interactions. Once a code for the interaction was selected from the categories and behavioral codes, a subwindow opened automatically to record the specific socializing agent by whom the behavior was conducted. This enabled continuous recording of dyadic or multiple interactions of the child with socializing agents in the natural setting.

The software was field tested, and necessary modifications were made to adjust the look and feel of the recording screens (size of the screen areas, size of the characters, and how the codes appear during scoring) for efficient use by the examiner. 
An automated ringing of an alarm system was set at $1 \mathrm{~h}$ from the start of observation to help the examiner to stop coding the behaviors at the end of the session and to save the recording by closing the session. To ensure proper battery backup, a pair of lithium ion batteries were used. Data were synchronized daily between Palm and desktop, using 'HOTSYNC' operation facility; time and date were also checked for discrepancies. An in-house-designed software was used to convert the Palm database files to an Access database, which could be read into an SPSS database for analysis.

Reliability and training. Careful training of examiners and establishing their reliability are important parts of data collection. Examiners were trained to record observations, using BASIS installed on a Palm handheld device, from videotapes/natural observations of the interactions of sample children. A customized software was designed to check the reliability of the observations of the same child conducted simultaneously by two examiners. A time lag of up to $2 \mathrm{sec}$ in the recordings of a particular observation between the two examiners was set to count as no error in the software. The criteria used for identifying an error in the software were a mismatch of timing and a mismatch of behavioral codes at a given time. The omission of a behavioral code was also recorded as an error. To assess the interobserver reliability, kappa statistic (as a measure of agreement) and Pearson's product-moment correlation (as a measure of association) were also calculated. The overall kappa values on interobserver agreement was .77 $(p<.001)$, and Pearson's product-moment correlation was $r=.89(p<.001)$, which are considered as a high order of reliability in behavioral observations.

Subjects and setting. To test the software in the field, we conducted the study among 573 children, 2-4 years of age, in Sangam Vihar, a low to middle income periurban population in Delhi, India. These children were part of an ongoing, large, randomized, controlled trial (Sazawal et al., 2004).

Verbal informed consent was obtained from parents of the study children. The study was approved by the Committee for Human Research Review at Johns Hopkins University and by Annamalai University, India.

Recording observations in the field. The examiner carried the Palm to the child's house and conducted continuous, direct observations of the child-socializing agents' interactions for $1 \mathrm{~h}$ in the natural setting. Daily, 4 children were scheduled for assessments; their mothers were informed on the previous day and were told to stay at home on the day of the assessment. The identification data for the scheduled children were uploaded into the Palm database in the Palm, using custom-designed software on desktop at the base station on the day previous to the assessment. The children were rescheduled for another day in cases of illness or not being available. The examiner, on reaching the child's home, selected the desired child from the list of children before the start of the assessment. The mother was advised not to limit the child's natural activity, and the child was allowed to go anywhere he/she wanted. The examiner followed the child and recorded observations continuously for $1 \mathrm{~h}$ without distracting the child. The examiner noted any errors in recording the interactions of the child with socializing agents and edited it at the base station after having downloaded data into the desktop, using the customized Edit software of BASIS. Figure 1 shows a flowchart of the development of BASIS and the recording of observations using it.

Two full observations of the children were done in a single Palm, after which the examiner downloaded the data from the Palm and next day's scheduled children were uploaded. Figures 2 and 3 show data entry screens of BASIS for the Palm handheld device and Palm database file observations of a child, respectively.

A separate precoded form was filled in to record the time for which the mother, father, siblings, peers, and neighbors were present in the environment of the child during the observation session.

Outcome measures. Outcome measures for each of the socializing agents included affection, aggression, indif-

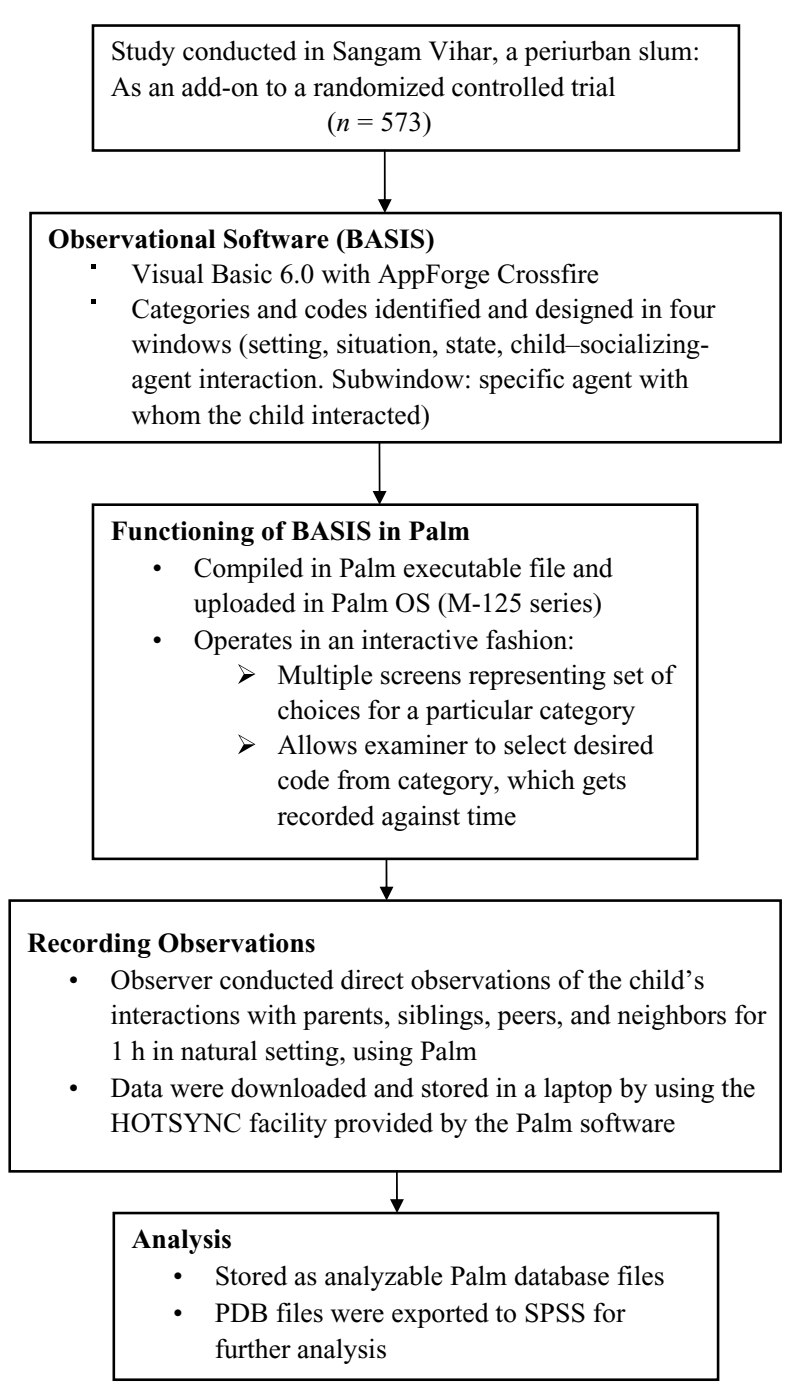

Figure 1. BASIS software for recording children's interactions. 


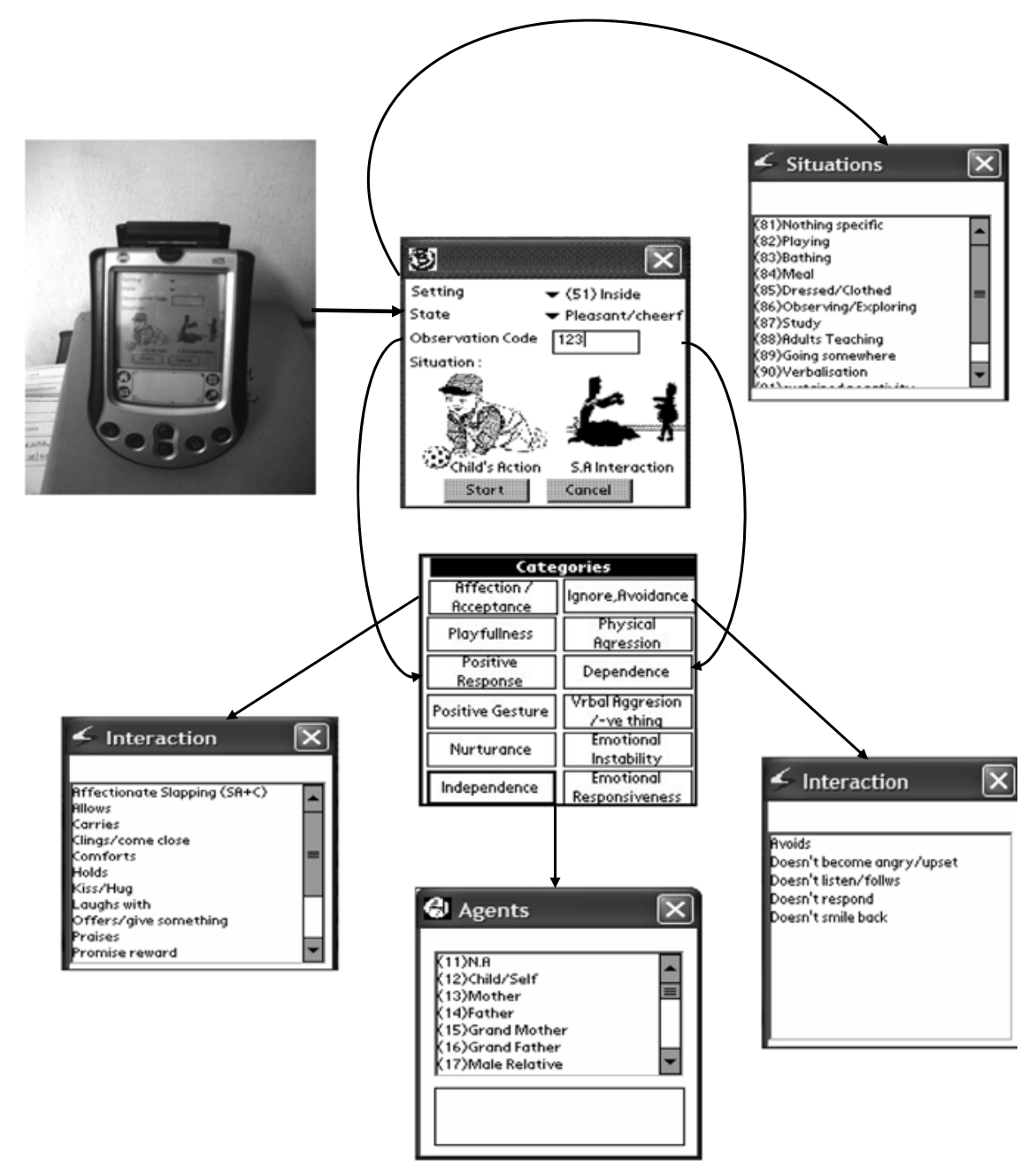

Figure 2. Screen shots of some data entry screens of BASIS for recording observations.

ference, nurturance, response, and playfulness. Affection was operationalized as a demonstration of spontaneous warmth, affection, and sense of responsibility toward the child. Neglect was characterized by a restricted concern for the child's safety or needs. Aggression was defined as any overt action or gesture that was intended to hurt physically or verbally. The child's measures included aggression, self-reliance behavior, positive feeling, emotional instability, and responsiveness to others. Independence of the child was operationalized as the child's trying to do work independently, not seeking sympathy, not seeking proximity, or demanding attention. Emotional instability of the child was characterized as the child's displaying impulsive behavior or getting upset with mild reprimanding or problems. Responsiveness of the child was characterized as his positive response toward others' affectionate advances or expressions of comfort or sympathy or concern for others.

Analysis. After downloading all of the observations from the Palm database, these were programmatically summarized for each child in the Access database. This was then exported to SPSS 12.0 for further categorization and analysis. The codes of a particular outcome variable were collated, and the frequency and percentage of each of these outcome measures for the children and their socializing agents were calculated. The behaviors were categorized as never occurred, occasionally occurred for behaviors that occurred up to two times, and frequently occurred for behaviors that occurred more than two times during the entire observation session. The mean occurrences of behavioral categories were also calculated.

\section{Results}

In a sample of 573 children, using BASIS installed on the Palm OS handheld device, we successfully observed and recorded the social interactions of children with socializing agents, and vice versa, for $60 \mathrm{~min}$. The data presented in this section are mainly for illustrative purposes, to show the kind of behavioral information about social interactions that can be collected using BASIS.

A total of 90,168 behavioral sequences were recorded in the software, and an average of 156 behavioral observa- 


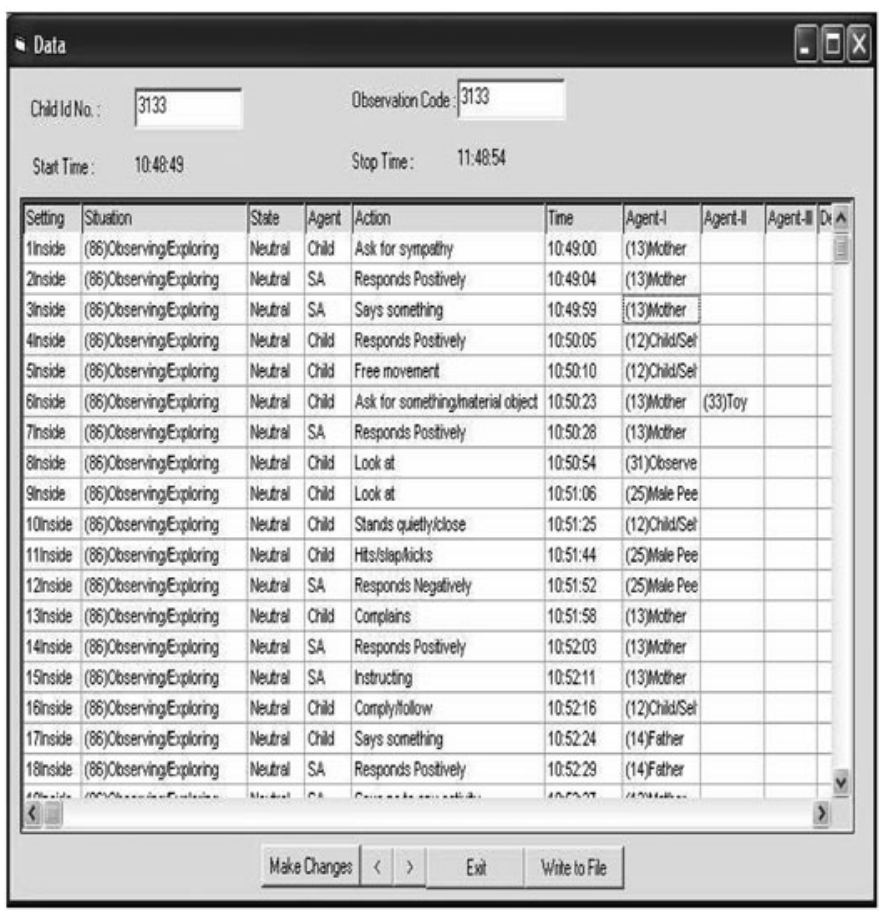

Figure 3. Screen shot of observations recorded with Palm being downloaded into Palm database (PDB) format.

tions of a child were made per observation session. Of the mothers, $97 \%$ were present throughout the observation session. Of the children, $76 \%$ had siblings and $46 \%$ had peers present throughout the session. Fathers were present in fewer than $20 \%$ of the observation sessions of the children.

The mothers' interactions with the children during the observations showed that only $30 \%-35 \%$ of the mothers displayed frequent nurturing behavior (active caretaking) and playfulness. The rest of them either did not show or occasionally showed nurturing or playful behavior toward the children. However, $82 \%$ of the mothers responded positively to any query or initiation by the child. This shows that although fewer mothers initiated frequent affectionate behavior toward the children, most of them responded positively to any initiation of the children toward them. Physical aggression toward the children was rare, although $27 \%$ of the mothers exhibited frequent instances of verbal aggression. Of mothers, $68 \%$ showed occasional or frequent instances of indifference/neglect toward the children (Table 1). During the observation session, the mothers showed more frequent instances of positive/acceptance behavior (such as motherly affection, nurturance, playfulness, or positive response; mean $\pm S D$, $15.3 \pm 10.2)$ as compared with negative/rejection behavior (verbal/physical aggression, indifference) toward the children (mean $\pm S D, 6.1 \pm 4.7$ ).

An analysis of the children's interactions with socializing agents during the observation sessions showed that $14 \%$ of the children had demonstrated instances of ag- gressive behavior (Table 2). Only $46 \%$ of the children displayed frequent expressions of positive feeling, such as smiling and responding. Most of the children displayed frequent acts of self-reliant behavior (mean $\pm S D, 12.4 \pm$ 7.3) and emotional responsiveness to others (mean $\pm S D$, $20.7 \pm 9.4$ ). All the children exhibited few instances of physical/verbal aggression toward others during the session (mean $\pm S D, 1.89 \pm 1.6$ ).

The children's interactions with fathers and neighbors were minimal, and the only frequent interactions were positive responses upon the children's initiation (Tables 3 and 4). On average, neighbors displayed few instances of positive behavior toward the children during the observation sessions (mean $\pm S D, 1.62 \pm 0.51$ ).

An analysis of siblings' interactions during the observation sessions showed that $20 \%$ of the siblings exhibited instances of affectionate and playful behavior toward the

Table 1

Observation of Mothers' Behavior Using BASIS

\begin{tabular}{|c|c|c|c|c|c|c|}
\hline \multirow{3}{*}{$\begin{array}{c}\text { Variable } \\
\text { (Mothers' Behavior } \\
\text { Toward the Children } \\
\text { During the Sessions) }\end{array}$} & \multicolumn{6}{|c|}{ Occurrences During Observations } \\
\hline & \multicolumn{2}{|c|}{ None/Never } & \multicolumn{2}{|c|}{ Occasional } & \multicolumn{2}{|c|}{ Frequent } \\
\hline & No. & $\%$ & No. & $\%$ & No. & $\%$ \\
\hline Nurturance & 184 & 32. & 18 & 32. & 21 & 35.4 \\
\hline Playfulness & 190 & 33.2 & 210 & 36.6 & 173 & 30.2 \\
\hline Positive response & 39 & 6.8 & 66 & 11.5 & 468 & 81.7 \\
\hline Physical aggression & 510 & 89.0 & 55 & 9.6 & 8 & 1.4 \\
\hline Verbal aggression & 237 & 41.4 & 177 & 30.9 & 159 & 27.7 \\
\hline Neglect/indifference & 170 & 29.7 & 191 & 33.3 & 212 & 37.0 \\
\hline
\end{tabular}


Table 2

Observation of Children's Behavior Using BASIS

\begin{tabular}{|c|c|c|c|c|c|c|}
\hline \multirow{3}{*}{$\begin{array}{c}\text { Variable } \\
\text { (Children's Behavior } \\
\text { Toward Other } \\
\text { Socializing Agents } \\
\text { During the Sessions) }\end{array}$} & \multicolumn{6}{|c|}{ Occurrences During Observations } \\
\hline & \multicolumn{2}{|c|}{ None/Never } & \multicolumn{2}{|c|}{ Occasional } & \multicolumn{2}{|c|}{ Frequent } \\
\hline & No. & $\%$ & No. & $\%$ & No. & $\%$ \\
\hline Physical aggression & 315 & 55.0 & 179 & 31.2 & 79 & 13.8 \\
\hline Verbal aggression & 329 & 57.4 & 190 & 33.2 & 54 & 9.4 \\
\hline Positive feeling & 94 & 16.4 & 216 & 37.7 & 263 & 45.9 \\
\hline Independence & 7 & 1.2 & 23 & 4.0 & 543 & 94.8 \\
\hline Dependence & 267 & 46.6 & 219 & 38.2 & 87 & 15.2 \\
\hline Emotional instability & 234 & 40.8 & 193 & 33.7 & 146 & 25.5 \\
\hline Emotional responsiveness & 2 & 0.3 & 6 & 1.0 & 565 & 98.6 \\
\hline
\end{tabular}

children. Of the siblings, $50 \%$ responded positively to initiation by the children, whereas only $8 \%$ of the siblings exhibited positive gestures toward the children (Table 5). The siblings exhibited few instances of affectionate behavior toward the children during the sessions (mean \pm $S D, 1.21 \pm 1.13)$. The interactions with peers were mainly playfulness and positive responses (Table 6).

\section{Discussion}

In our experience, BASIS installed on the Palm OS handheld device is an innovative attempt that causes a significant improvement in the ability to use a computerized behavioral recording system for observing children's complex interactions with multiple socializing agents, such as parents, neighbors, siblings, and peers. The results indicate that with the comprehensive coding scheme that we developed for recording observations with this software, we could record almost all kinds of behavior important from the perspective of children's social behavior and interactions. It also gave an insight into the simple and easily understandable behavioral outcomes that were deduced from the complex data on child-socializing agents' interactions. Thus, BASIS enabled us to adopt a microassessment approach for recording diverse observations on childsocializing agents' interaction in the natural setting.

BASIS in Palm OS is able to provide a better alternative, in comparison with manual methods, for which analysis and recording are complex (Bakeman \& Gottman, 1986; Berdondini et al., 1999). The kind of comprehensive recording and data collection on child-socializing agents' interactions that we wanted was not possible with manual

Table 3

Observation of Fathers' Behavior Using BASIS

\begin{tabular}{|c|c|c|c|c|c|c|}
\hline \multirow{3}{*}{$\begin{array}{c}\text { Variable } \\
\text { (Fathers' Behavior } \\
\text { Toward the Children } \\
\text { During the Sessions) }\end{array}$} & \multicolumn{6}{|c|}{ Occurrences During Observations } \\
\hline & \multicolumn{2}{|c|}{ None/Never } & \multicolumn{2}{|c|}{ Occasional } & \multicolumn{2}{|c|}{ Frequent } \\
\hline & No. & $\%$ & No. & $\%$ & No. & $\%$ \\
\hline Affection & 53 & 9 & 28 & 4. & 7 & 1.2 \\
\hline Playfu & 526 & 91.8 & 34 & 5.9 & 13 & 2.3 \\
\hline Positive response & 472 & 82.4 & 44 & 7.7 & 57 & 9.9 \\
\hline Positive gesture & 559 & 97.6 & 14 & 2.5 & - & \\
\hline Physical aggression & 570 & 99.5 & 3 & 0.5 & - & \\
\hline Verbal aggression & 544 & 94.9 & 22 & 3.8 & 7 & 1.2 \\
\hline
\end{tabular}

recording. Although, earlier, we had tried to do this recording using manual methods, we were not able to record the observations efficiently.

Recently, observational software has come into use due to ease of recording, storing, and analysis of complex behavioral observations and reducing data entry errors. Observer 5.0 (Noldus Information Technology, 2003) is a widely used software for the collection of observational data. Our observational software in the Palm OS handheld device is a laptop-based continuous observation system that has the virtues of ease of accurately recording diverse behaviors, observing greater numbers of interactions, reducing data entry errors, and achieving high interobserver reliability. In addition, our system is a lowcost and mobile option for recording data in field settings in developing countries. However, as compared with the laptop-based Observer system, Palm OS has the limitation of a small screen that may slightly reduce continuous observation; but the loss is very minimal to be of significance. Although the small screen of the Palm OS device is a potential limitation, in our case, with adequate training and practice, we could easily use it for recording childsocializing agents' interactions in the field setting.

Pocket Observer, which is a version of the Observer 5.0 designed for use in handheld computers, in some ways functionally provides an option similar to our software in Palm OS (M-125 series). These similarities include mobility of use, easy HOTSYNC operation for uploading and downloading from desktop/laptop, which saves time in field settings, lithium ion batteries for long use, and use of a stylus for selecting and recording behavioral codes. However, Pocket Observer works only on limited specialized PDA handheld devices that are expensive in themselves, with an additional cost of the software, in comparison with the Palm OS (M-125 series), which costs less than $\$ 75$. Using the built-in analysis program in Observer 5.0 is time consuming, especially when processing a large sample of data. Moreover, the output generated is limited only to profiles and still requires statistical analysis. BASIS did not have built-in analysis software, but the Access database from the Palm database files could easily be exported to any statistical database for further analyses.

Roberts (2002) also has developed observational software, Focal 32, to record the interactions of children, 
Table 4 Observation of Neighbors' Behavior Using BASIS

\begin{tabular}{|c|c|c|c|c|c|c|}
\hline \multirow{3}{*}{$\begin{array}{c}\text { Variable } \\
\text { (Neighbors' Behavior } \\
\text { Toward the Children } \\
\text { During the Sessions) }\end{array}$} & \multicolumn{6}{|c|}{ Occurrences During Observations } \\
\hline & \multicolumn{2}{|c|}{ None/Never } & \multicolumn{2}{|c|}{ Occasional } & \multicolumn{2}{|c|}{ Frequent } \\
\hline & No. & $\%$ & No. & $\%$ & No. & $\%$ \\
\hline Affect & 513 & 89.5 & 52 & $9 .($ & 8 & 1.4 \\
\hline Playfulness & 514 & 89.7 & 53 & 9.3 & 6 & 1.0 \\
\hline Positive response & 454 & 79.2 & 95 & 16.6 & 24 & 4.1 \\
\hline Positive gesture & 565 & 98.6 & 8 & 1.4 & - & \\
\hline Physical aggression & 562 & 98.1 & 10 & 1.7 & 1 & 0.2 \\
\hline Verbal aggression & 508 & 88.7 & 57 & 9.9 & 8 & 1.4 \\
\hline
\end{tabular}

Table 5

Observation of Siblings' Behavior Using BASIS

\begin{tabular}{|c|c|c|c|c|c|c|}
\hline \multirow{3}{*}{$\begin{array}{l}\text { Variable } \\
\text { (Siblings' Behavior } \\
\text { Toward the Children } \\
\text { During the Sessions) }\end{array}$} & \multicolumn{6}{|c|}{ Occurrences During Observations } \\
\hline & \multicolumn{2}{|c|}{ None/Never } & \multicolumn{2}{|c|}{ Occasional } & \multicolumn{2}{|c|}{ Frequent } \\
\hline & No. & $\%$ & No. & $\%$ & No. & $\%$ \\
\hline Affection & 451 & 78.7 & 97 & 16.9 & 25 & 4.4 \\
\hline Playfulness & 400 & 69.8 & 122 & 21.3 & 5 & 8.9 \\
\hline Positive response & 277 & 48.3 & 120 & 22.6 & 166 & 29.0 \\
\hline Positive gesture & 522 & 91.1 & 48 & 8.4 & 3 & 0.5 \\
\hline Physical aggression & 494 & 86.2 & 74 & 12.9 & 4 & 0.9 \\
\hline Verbal aggression & 492 & 85.9 & 61 & 10.7 & 20 & 3.4 \\
\hline
\end{tabular}

using a laptop. However, this computerized method has limitations; the examiner has to remember more than 100 behavioral codes as numeric codes, there are problems in mobility due to the use of a laptop, and the examiner has to define the context and persons involved in the observation session before the start of the observation session or whenever any change occurs. Similarly, with Pocket Observer, while recording observations, the examiner has to remember the key codes, since he/she has to tap the required code from a display of all the key codes for that particular behavior.

In contrast, our observation system is more user friendly, since all the codes of behaviors are displayed in short sentences in their respective multiple interfacing windows, in which the examiner has to click the desired codes. There was, thus, no need for the examiners to memorize the codes or abbreviations, and this facilitated easy selection and recording of multiple codes during the observation sessions. The "situation" and the "agent" subwindows al-

Table 6

Observation of Peers' Behavior Using BASIS

\begin{tabular}{|c|c|c|c|c|c|c|}
\hline \multirow{3}{*}{$\begin{array}{c}\text { Variable } \\
\text { (Peers' Behavior } \\
\text { Toward the Children } \\
\text { During the Sessions) }\end{array}$} & \multicolumn{6}{|c|}{ Occurrences During Observations } \\
\hline & \multicolumn{2}{|c|}{ None/Never } & \multicolumn{2}{|c|}{ Occasional } & \multicolumn{2}{|c|}{ Frequent } \\
\hline & No. & $\%$ & No. & $\%$ & No. & $\%$ \\
\hline Nurturance & 533 & 93.0 & 34 & 5.9 & 6 & 1.0 \\
\hline Playfulness & 440 & 76.8 & 109 & 36.6 & 24 & 4.2 \\
\hline Positive response & 317 & 55.3 & 149 & 26.0 & 107 & 18.7 \\
\hline Physical aggression & 509 & 88.8 & 60 & 10.5 & 4 & 0.7 \\
\hline Verbal aggression & 531 & 92.7 & 41 & 7.2 & 1 & 0.2 \\
\hline Neglect/indifference & 441 & 77.0 & 121 & 21.1 & 11 & 1.9 \\
\hline Positive gesture & 520 & 90.8 & 50 & 8.7 & 3 & 0.5 \\
\hline Affection & 481 & 83.9 & 82 & 14.3 & 10 & 1.7 \\
\hline
\end{tabular}

lowed us to record the child's context (as broad activity) and the persons interacting with the study child.

One of the limitations of BASIS in Palm OS was that the examiners required long practice and training sessions to achieve the desired level of reliability, due to the multiple screens, the large number of codes, and the frequently changing movements and interactions of children with multiple socializing agents. However, we required comprehensive data on child-socializing agents' interactions, since these were to be used for evaluating part of the intervention effects in a randomized, controlled clinical trial.

Although laptop-based systems such as Observer 5.0 are better for continuous recording of observations where cost is not a constraint and setting does not require mobility, the multiple advantages of BASIS in Palm OS make it a low-cost, preferable alternative for assessing children's interactions with multiple socializing agents in natural settings. In addition, the codes and categories used in this software are of a global nature, which can be used for recording the social interactions of children in other settings as well. This promising new software needs to be tested further.

\section{REFERENCES}

Ainsworth, M. D. S., Blehar, M. C., Waters, E., \& Wall, S. (1978). Patterns of attachment: A psychological study of the strange situation. Hillsdale, NJ: Erlbaum.

Bakeman, R., \& Gottman, J. M. (1986). Observing interaction: An introduction to sequential analysis. Cambridge: Cambridge University Press.

BARNARD, K. E. (1979). Instructor's learning resource manual. Seattle: University of Washington, NCAST.

Berdondini, H., Cowie, A., Almeida, A., Isidro, B. M., Lera, J., \& Ortega, R. (1999). An observational approach to study social and aggressive behaviour of children (Report of Working Party chaired by Angela Costabile). Calabria, Italy: Università degli Studi della Calabria.

Bronfenbrenner, U. (1986). Ecology of the family as a context for human development: Research perspectives. Developmental Psychology, 22, 723-742.

Caldwell, B. M., \& Bradley, R. H. (1978). Manual for the home observation for measurement of the environment. Little Rock: University of Arkansas.

Cardone, I. A., \& Gilkerson, L. (1990). Family administered neonatal activities: An exploratory method for integration of parental perceptions and newborn behavior. Infant Mental Health Journal, 11, 127141 .

CLARK, R. (1985). The parent-child early relational assessment. Madison: University of Wisconsin Medical School, Department of Psychiatry.

Clark, R., Musick, J., Stott, F. M., Klehr, K. B., \& Cohler, B. J. (1984). Mother-child dyads at risk: Development of rating scales for early identification of disturbances in affect and behavior [Abstract]. Infant Behavior \& Development, 7, 72.

Clark, R., Paulson, A., \& Conlin, S. (1993). Assessment of developmental status and parent-infant relationships: The therapeutic process of evaluation. In C. H. Zeanah, Jr. (Ed.), Handbook of infant mental health (pp. 191-209). New York: Guilford.

Coplan, R., \& PARKe, R. (1999, April). Parents and children's peer interactions and relationships. Paper presented at the SRCD Preconference Workshop on Peer Relationships and Social Skills, Albuquerque, NM.

Demos, V. (1982). The role of affect in early childhood: An exploratory study. In E. Z. Tronick (Ed.), Social interchange in infancy: Affect, cognition, and communication (pp. 79-137). Baltimore: University Park Press. 
EmDE, R. N. (1980). Emotional availability: A reciprocal reward system for infants and parents with implications for prevention of psychosocial disorders. In P. Taylor (Ed.), Parent-infant relationships (pp. $87-$ 115). New York: Grune \& Stratton.

FARran, D., Clark, K., \& RAY, A. (1990). Measures of parent-child interaction. In E. D. Gibbs \& D. Teti (Eds.), Interdisciplinary assessment of infants: A guide for early intervention professionals (pp. $227-$ 248). Baltimore: Brookes Publishing.

GreensPan, S. I., \& LeIBERMan, A. (1980). Infants, mothers and their interactions: A quantitative clinical approach to developmental assessment. In S. I. Greenspan \& G. H. Pollock (Eds.), The course of life: Psychoanalytic contributions toward understanding personality development. Vol. 1: Infancy and early childhood. (DHHS Publication No. ADM 80-786, pp. 271-312). Washington, DC: U.S. Government Printing Office.

HoFf, E. (2003). The specificity of environmental influence: Socioeconomic status affects early vocabulary development via maternal speech. Child Development, 74, 1368-1378.

Horodynski, M. A., \& GibBons, C. (2004). Rural low-income mothers' interactions with their young children. Pediatric Nursing, 30, 299-306.

Humber, N., \& Moss, E. (2005). The relationship of preschool and early school age attachment to mother-child interaction. American Journal of Orthopsychiatry, 75, 128-141.

Koop, A., \& Mösges, G. (2001). The use of handheld computers in clinical trials. Controlled Clinical Trials, 23, 469-480.

Martin, P., \& Bateson, P. (1986). Measuring behavior: An introductory guide. Cambridge: Cambridge University Press.

Noldus Information Technology (2003). The Observer (Version 5):
Professional system for collection, analysis, presentation and management of observational data. Reference manual. Wageningen: Noldus Information Technology.

Plant, R. P., Hammond, N., \& Turner, G. (2004). Self-validating presentation and response timing in cognitive paradigms: How and why? Behavior Research Methods, Instruments, \& Computers, 36, 291-303.

Pollitt, E., Saco-Pollitt, C., Jahari, A., Husaini, M. A., \& HuANG, J. (2000). Effects of an energy and micronutrient supplement on mental development and behavior under natural conditions in undernourished children in Indonesia. European Journal of Clinical Nutrition, 54(Suppl. 2), S80-S90.

Roberts, W. (2002). Programs for the collection and analysis of observational data: Manual for the beta Windows 98 version. Kamloops, BC: University College of the Cariboo. Available at www.tru.ca/ae/psych/ faculty/roberts/observationprogramsmanual.pdf.

RoHNER, R. P. (1999). Handbook for the study of parental acceptance and rejection. Storrs: University of Connecticut Press.

Sazawal, S., Dhingra, U., Sarkar, A., Dhingra, P., Deb, S., MARWAH, D., ET AL. (2004). Efficacy of milk fortified with a probiotic Bifidobacterium lactis (DR-10 ${ }^{\mathrm{TM}}$ ) and prebiotic galacto-oligosaccharides in prevention of morbidity and on nutritional status. Asia Pacific Journal of Clinical Nutrition, 13(Suppl.), S28.

Selanikio, J. D., Kemmer, T. M., Bovill, M., \& Geisler, K. (2002). Mobile computing in the humanitarian assistance setting: An introduction and some first steps. Journal of Medical Systems, 26, 113-125.

Vygotsky, L. S. (1979). Mind in society: The development of higher psychological processes. Cambridge, MA: Harvard University Press. 
APPENDIX

Codes Used in BASIS for Recording Children's Interactions With Their Socializing Agents

\section{Setting of the Child (Location)}

Inside/outside the house

\section{Situation (Broad Activity) of the Child}

Doing nothing specific (passive), playing, bathing, having meal, dressed/clothed (by socializing agent), observing/exploring, studying, adult teaching, going somewhere, verbalization (sustained talking/narration), sustained negativity (such as crying, getting angry), taking care, performing skill activity, others

\section{State of the Child}

Shy, fearful, drowsy, sleepy, angry/upset, neutral, pleasant/cheerful

\section{Interaction Categories and Codes for Child and Socializing Agent}

Affection/acceptance. Socializing agent accepts, affectionate slapping, allows, carries, clings/comes close, comforts, holds, kisses/hugs, laughs with, offers/gives something, praises, promises reward, helps, smiles, takes, touches, offers money, toy, or things, calls child by pet name

Playfulness. Socializing agent imitates an activity, includes in activity, initiates play, interrupts an activity/conversation, makes playful sounds, negotiates/exchanges objects/work, nothing specific, plays, sings and dances with child

Positive response. Socializing agent comforts, consoles, shows sympathy, responds positively, persuades, instructs, helps/tries to do something, shows concern toward the child

Positive gesture. Socializing agent shows something, smiles back, laughs with, watches with interest, looks at child, refers positively about child to someone

Verbal aggression/negative thing. Socializing agent argues, complains, demands persistently, denies guilt, gives up/leaves things, provokes by saying/doing something, rejects, resists, ridicules, says negative things about child, says no to any activity, scolds, screams/shouts, shows stubbornness over something, uses abusive language, responds negatively to child or vice versa

Ignore, avoidance. Socializing agent avoids, doesn't become angry/upset, doesn't listen/follow, doesn't respond, doesn't smile back, ignores/doesn't show concern when the child is in danger, stops talking to child, refers negatively about child to someone

Nurturance. Socializing agent applies, breast feeds, cleans body parts, combs, eats/drinks, feeds, looks after, puts on lap, puts on/off slippers/others things, puts on/off clothes, puts to sleep, takes/give baths, takes the child to toilet, applies medicines/cosmetics, offers food/water to child

Physical aggression. Socializing agent slaps, bites, scratches, pushes, breaks, throws/destroys, destroys things/child's things, drags, kicks, pulls hair/clothes, snatches, threatens to hit, slaps, punishes, threatens in the name of others, throws things, destroys/disorganizes, snatches child's toys or vice versa

Independence. Child performs skill activity, walks, picks something, eats on own, closes/opens door/gate, gets up/down, runs, jumps, reads, sings, dances, plays, tries to do something on his/her own, instructs, persuades/convinces

Dependence. Child asks someone to do an activity, asks for help, seeks attention, interrupts conversation/any activity of mother, cries/screams (preceded by mother moving away, or when any agent hits or scolds or snatches anything from the child), goes after mother, asks for sympathy

Emotional instability. Child gets upset/angry, withdraws suddenly, cries suddenly preceded by scolding/ corporal punishment from adult, denies guilt

Emotional responsiveness. Child responds positively, looks smilingly, talks to somebody, says something, smiles, laughs with, praises (other than self), hugs/kisses, helps, expresses sympathy, allows others, shows affection, seeks permission, complies/folvlows, listens, teaches 